\title{
Study on the Transverse impact characteristics of Al/CFRP Hybrid Square Hollow Section Beam
}

\author{
Sang Young Kim ${ }^{1}$, Jun Yeob Kim², Ju Won Jeong ${ }^{3}$, Kum Cheol Shin ${ }^{4}$ and Jung Ju Lee*
}

\begin{abstract}
In this paper, transverse impact characteristics of Al/CFRP hybrid beam were studied to increase structural stiffness and energy absorption for an application of lightweight vehicle body structure. Impact speed was set to meet the regulation of Federal Motor Vehicle Safety Standards (FMVSS) 214. The Energy absorption of Aluminum (Al)/Carbon Fiber Reinforced Polymer (CFRP) hybrid square hollow section (SHS) beam were evaluated under three point bending impact. The Specific Energy Absorption (SEA) was computed for five different lay-up sequences and two cases of CFRP thickness.
\end{abstract}

Keywords - Al/CFRP hybrid beam, energy absorption, transverse impact

\section{INTRODUCTION}

$\mathrm{E}$ NVIRONMENTAL regulations are more and more restrict requiring high energy efficiency. For low energy usage, lightweight vehicle body is necessary. However designing lightweight vehicle body causes decreasing of structural stiffness. To solve this problem, CFRP is introduced due to high specific modulus and strength. Kim[1,2] showed that Al/CFRP hybrid beam is possible to replace side door impact beam in the vehicle. Since almost side door impact beam is made from steels it is heavy and not good for energy efficiency. In his paper, he found the failure mechanism of Al/CFRP hybrid beam under quasi-static transverse loading. Because of brittle failure mode of CFRP, it is not suitable for energy absorber. However, failure mode of CFRP is changed to progressive manner by being guided of $\mathrm{Al}$ beam that has ductile fracture mode. Thus, $\mathrm{Al} / \mathrm{CFRP}$ hybrid beam is super-lightweight performing high energy absorption. Bambach[3,4] carried out quasi static under axial direction and axial impact loading. He also showed that steel/CFRP beam is possible for crash box application. Overall, metal/CFRP hybrid beam is a perfect choice to replace energy absorber of vehicle body assuring safety of passenger and energy efficiency.

In this research, following FMVSS 214 regulation, side

Jung Ju Lee ${ }^{*}$ is with Mechanical Engineering, Korea Advanced Institute of Science and Technology (KAIST), Daejeon, Republic of Korea.

Sang Young $\mathrm{Kim}^{2}$ is with Mechanical Engineering, KAIST, Daejeon, Republic of Korea.

Jun Yeob Kim ${ }^{3}$ is with Mechanical Engineering, KAIST, Daejeon, Republic of Korea.

Ju Won Jeong ${ }^{4}$, is with Mechanical Engineering, KAIST, Daejeon, Republic of Korea.

Kum Cheol Shin ${ }^{4}$ is with Mechanical system, Shin Ansan Univ., Ansan, Republic of Korea. impact test is conducted with a drop weight impact test machine that generate impact velocity of more than $50 \mathrm{~km} / \mathrm{h}$. Finally, the energy absorption capability and structural stiffness of the $\mathrm{Al}$ /CFRP hybrid SHS beam were compared to those of pure $\mathrm{Al}$ SHS beam. Also different cases changing lay-up sequence and thickness are compared to find the best case for side door impact beam.

\section{SPECIMEN FABRICATION}

As shown in figure 1, there are five lay-up sequence and two thicknesses. Composite materials including CFRP is obviously heterogeneous, with properties changing from point to point. Because of non-homogeneous properties, these lay-up sequence produced different mechanical characteristic in each case.
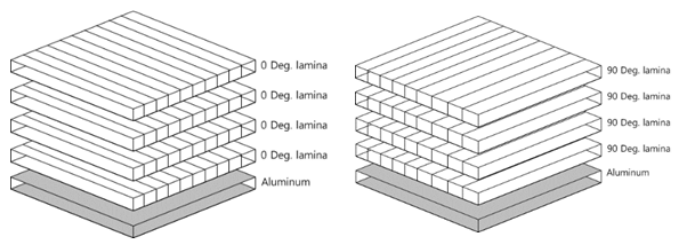

$[0]_{4 n}$
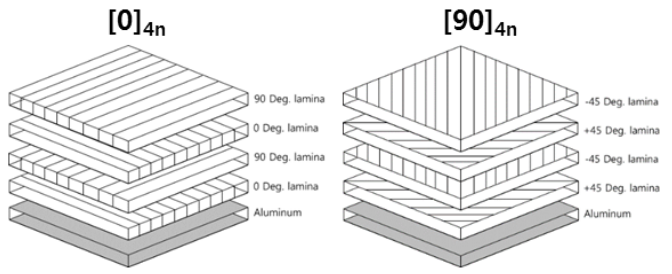

$[0 / 90]_{2 n}$

$[+45 /-45]_{2 n}$

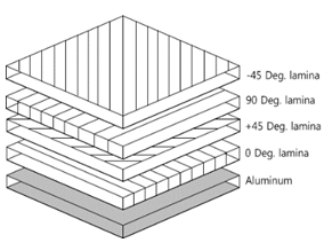

- thickness : $0.584 \mathrm{~mm}$

$(n=1$, lay up number : 4)

$[0 /+45 / 90 /-45]_{\mathrm{n}}$

- thickness : $1.168 \mathrm{~mm}$

$(n=2$, lay up number : 8$)$

Fig. 1 Stacking sequence and thickness

The size of Al SHS beam which is extruded from Al6063T5 is $45 \mathrm{~mm}$ X $45 \mathrm{~mm}$ X $200 \mathrm{~mm}$ with $1.4 \mathrm{~mm}$ thickness of wall. Unidirectional CFRP prepreg (USN150B, SK chemicals) reinforced this Al SHS beam. As shown in Fig. 2-(a), Al and laminated CFRP are co-cured in an autoclave after stacking CFRP in different angle. The curing cycle for epoxy is plotted in figure 2-(b) provided from manufacture company. 
(a)
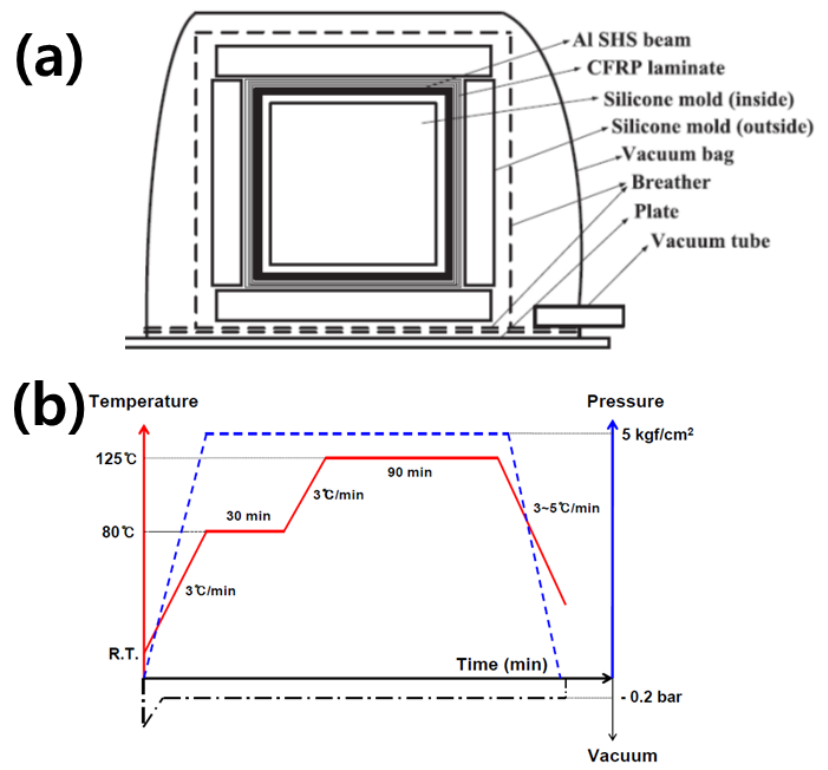

Fig. 2 (a) Diagram of vacuum bag (b) Curing cycle

Followings are solutions for increasing the interfacial adhesion strength. They are strongly recommended because the bonding between $\mathrm{Al}$ and CFRP is poor. First, 10um-grit blasting is applied on $\mathrm{Al}$ surfaces for a mechanical interlocking. Then we sank the $\mathrm{Al}$ in acetone bath with ultrasonic wave for $5 \mathrm{~min}$. And also we exposure $\mathrm{Al}$ in an atmosphere of Argon plasma. And last, one layer of film adhesive (FM300-k, CYTEC) is attached on $\mathrm{Al}$ before CFRP.

\section{DROP WEIGHT IMPACT TEST MACHINE}

Drop weight impact test is useful way to measure energy absorption and crashworthiness because of its low production cost and simpleness. Fig. 3-(a), (b) is the drop weight impact test machine producing up to 850J. Two spring are used to apply much more energy to the impactor. Piezoelectric force sensor measures the load when the impactor crashes the specimen described in Figure 3-(c).

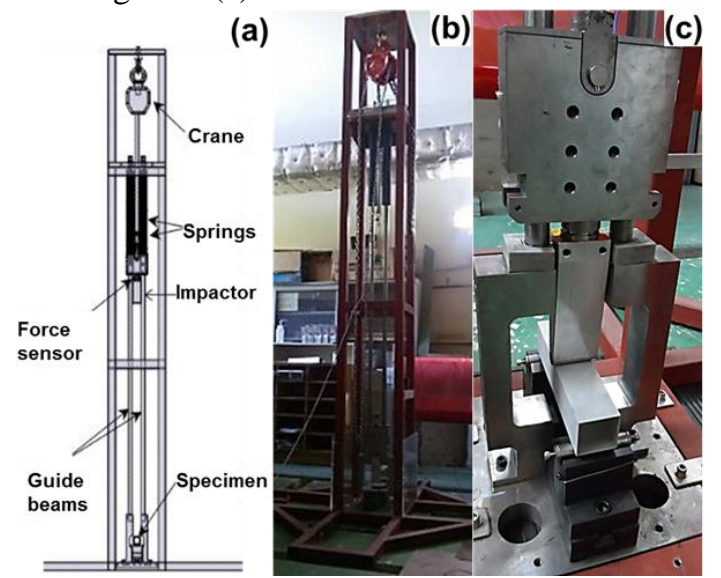

Fig. 3 (a), (b) Drop weight impact machine, (c) three point bending condition.

As shown in Fig. 3-(c), the three point bending test was carried out to simulate a side door impact beam using this drop weight impact test machine. Weight of the impactor was $7.5 \mathrm{~kg}$ and the impact velocity of impactor before crash was
$14.39 \mathrm{~m} / \mathrm{s}-15.38 \mathrm{~m} / \mathrm{s}$. The diameter of the impactor loading nose with cylindrical shape is $16 \mathrm{~mm}$. The test span wat set to $170 \mathrm{~mm}$. At once force sensor reads the load, it produced force-time curve. Finally, force-displacement curve can be acquired by double integration in eq (I).

$$
\delta(t)=\delta_{i}+v_{i} t+\frac{g t^{2}}{2}-\int_{0}^{t} \int_{0}^{t} \frac{F(t)}{m} d t d t
$$

where

$$
\begin{aligned}
& \delta=\text { impactor displacement at time } \mathrm{t} \\
& \delta_{\mathrm{i}}=\text { impactor displacement from reference location at time } \mathrm{t}
\end{aligned}
$$

\section{RESULTS}

The bending collapse and amount of energy absorption were observed by macroscopically with obtained force-displacement curve. From Fig. 4, amount of energy absorption can be obtained by calculating the area of force-displacement curve below. As shown in Fig. 4-(b), $[0 /+45 / 90 /-45]_{2}$ case have the highest energy absorption, and absorbed energy of this case was increased by $103 \%$ than that of pure Al SHS beam. For fair comparison, SEA information is necessary. The definition of SEA is entire energy absorption over sum of mass $[\mathrm{J} / \mathrm{g}]$. Comparing SEA is a reasonable method for a lightweight vehicle body.
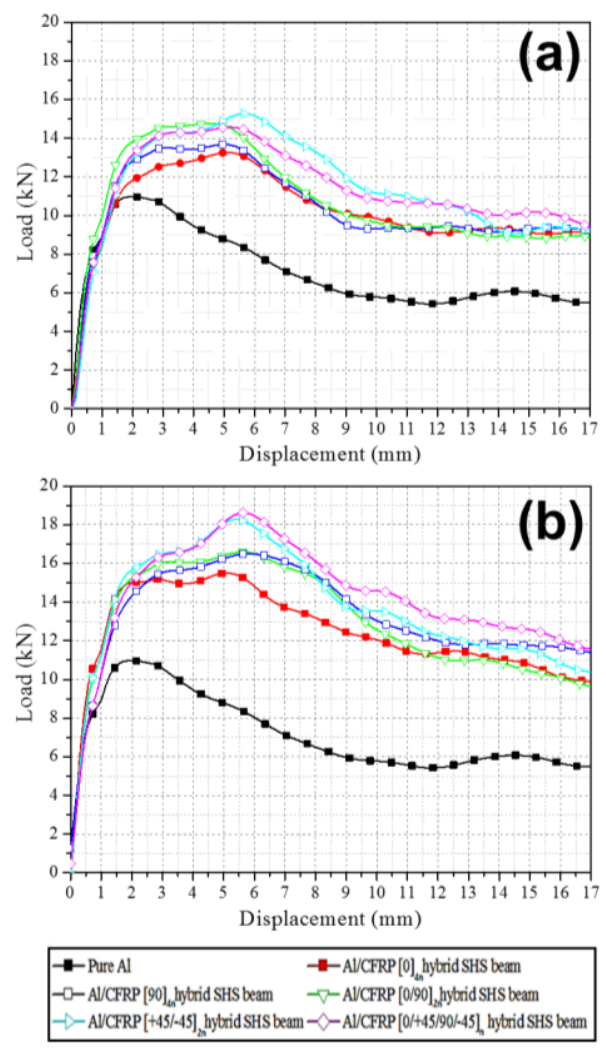

Fig. 4 Load-displacement curve for (a) 4 plies, (b) 8 plies

Moreover, SEA is influenced by not geometry but stacking sequence. Referring to Fig. 5, most of the specimens with eight plies has higher SEA, compared to those of the specimen with four plies. Because the wall thickness is a key parameter to 
thin-walled structures. Observing failure mode according to stacking sequence, there is severe debonding between $\mathrm{Al}$ surface and CFRP layer in [0] and [90] that results in low SEA. In the other cases, delamination in CFRP layers is dominant that leads to relatively high SEA. Also SEA was improved by $30 \%$ than pure Al SHS beam
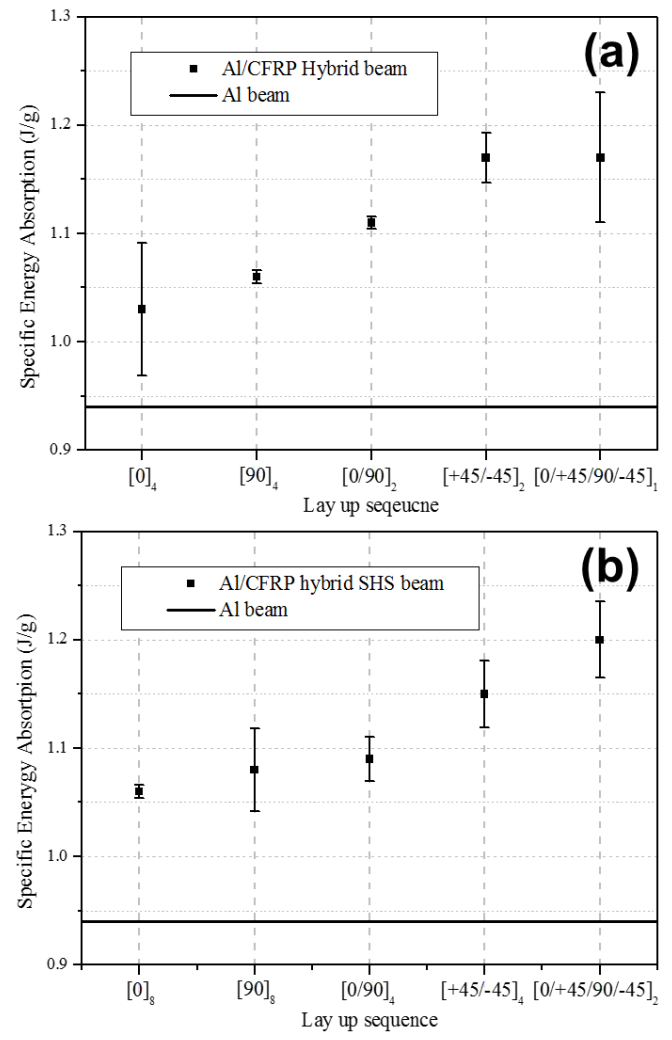

Fig. 5 SEA of hybrid beam (a) 4plies and (b) 8plies for each lay-up sequence.

\section{CONCLUSION}

Energy absorption characteristics of Al/CFRP hybrid SHS beam is investigated under three-point bending impact test. Failure mode was studied by macroscopically observing the damaged specimens and force-displacement curves. There were two experimental parameters: thickness, stacking sequence. For thickness, SEA of Al/CFRP hybrid beam in eight plies is higher than that of four plies. For stacking sequence, [0/+45/90/-45] is the highest SEA. Therefore, the energy absorption capacity and the SEA was remarkably improved than those of pure Al SHS beam.

\section{ACKNOWLEDGEMENTS}

This work was supported by the National Research Foundation of Korea (NRF) grant funded by the Korean government (MSIP) (No. 2010-0028680).

\section{REFERENCES}

[1] Kim HC, Shin DK, Lee JJ. Characteristics of aluminum/CFRP short square hollow section beam under transverse quasi-static loading. Compos Part B Eng 2013;51:345-58. doi:10.1016/j.compositesb.2013.03.020.

http://dx.doi.org/10.1016/j.compositesb.2013.03.020
[2] Kim HC, Lee JJ. The effects of interfacial adhesion strength on the characteristics of an aluminum/CFRP hybrid beam under transverse quasi-static loading. Compos Part B Eng 2014;67:595-606. doi:10.1016/j.compositesb.2014.06.017.

http://dx.doi.org/10.1016/j.compositesb.2014.06.017

[3] Bambach MR, Elchalakani M, Zhao XL. Composite steel-CFRP SHS tubes under axial impact. Compos Struct 2009;87:282-92. doi:10.1016/j.compstruct.2008.02.008.

http://dx.doi.org/10.1016/j.compstruct.2008.02.008

[4] Bambach MR, Elchalakani M. Plastic mechanism analysis of steel SHS strengthened with CFRP under large axial deformation. Thin-Walled Struct 2007;45:159-70. doi:10.1016/j.tws.2007.02.004.

http://dx.doi.org/10.1016/j.tws.2007.02.004 